American Journal of Applied Sciences 5 (6): 653-658, 2008

ISSN 1546-9239

(C) 2008 Science Publications

\title{
The Advantages of PID Fuzzy Controllers Over The Conventional Types
}

\author{
Abdullah I. Al-Odienat, Ayman A. Al-Lawama \\ Electrical Engineering Department. Faculty of Engineering \\ Mutah University
}

\begin{abstract}
Fuzzy logic controllers (FLC's) have the following advantages over the conventional controllers: they are cheaper to develop, they cover a wider range of operating conditions, and they are more readily customizable in natural language terms. A self-organizing fuzzy controller can automatically refine an initial approximate set of fuzzy rules. Application of PI-type fuzzy controller increases the quality factor. In this paper, the voltage raising type-pulse controller is considered. Two types of fuzzy controllers used for the control of boost converter are investigated; the simulation results confirm the above mentioned advantages. In order to prove the dynamic characteristics of the PID fuzzy controller being fast and robust, simulation studies using PSIM program are carried out and compared to the results of the conventional loop gain design method for which MATLAB program is used.
\end{abstract}

Key words: PI controllers, boost converters, Fuzzy controllers self-tuning fuzzy controllers

\section{INTRODUCTION}

Several research and industrial applications concentrated their efforts on providing simple and easy control algorithms to cope with the increasing complexity of the controlled processes/systems ${ }^{[1]}$. The design method for a controller should enable full flexibility in the modification of the control surface ${ }^{[2]}$. The systems involved in practice are, in general, complex and time variant, with delays and nonlinearities, and often with poorly defined dynamics. Consequently, conventional control methodologies based on linear system theory have to simplify/linearize the nonlinear systems before they can be used, but without any guarantee of providing good performance. To control nonlinear systems satisfactorily, nonlinear controllers are often developed. The main difficulty in designing nonlinear controllers is the lack of a general structure ${ }^{[3]}$. In addition, most linear and nonlinear control solutions developed during the last three decades have been based on precise mathematical models of the systems. Most of those systems are difficult/impossible to be described by conventional mathematical relations, hence, these model-based design approaches may not provide satisfactory solutions ${ }^{[4]}$. This motivates the interest in using FLC; FLCs are based on fuzzy logic theory ${ }^{[5]}$ and employ a mode of approximate reasoning that resembles the decision making process of humans. The behavior of a FLC is easily understood by a human expert, as knowledge is expressed by means of intuitive, linguistic rules.

In contrast with traditional linear and nonlinear control theory, a FLC is not based on a mathematical model and is widely used to solve problems under uncertain and vague environments, with high nonlinearities ${ }^{[6,7]}$. Since their advent, FLCs have been implemented successfully in a variety of applications such as insurance and robotics ${ }^{[8,9,10,11]}$. Fuzzy logic provides a certain level of artificial intelligence to the conventional PID controllers. Fuzzy PID controllers have self-tuning ability and on-line adaptation to nonlinear, time varying, and uncertain systems Fuzzy PID controllers provide a promising option for industrial applications with many desirable features.

\section{MATERIALS AND METHODS}

Fuzzy Controllers includes in their structure the following main components;

A. Fuzzification: Enabling the input physical signal to use the rule base, the approach is using membership functions. Four membership functions are given for the signals $e$ and $\dot{e}$ in Fig. 1 .

Corresponding Author: Abdullah I. Al-Odienat, Department of Electrical Engineering, Faculty of Engineering, Mutah University 


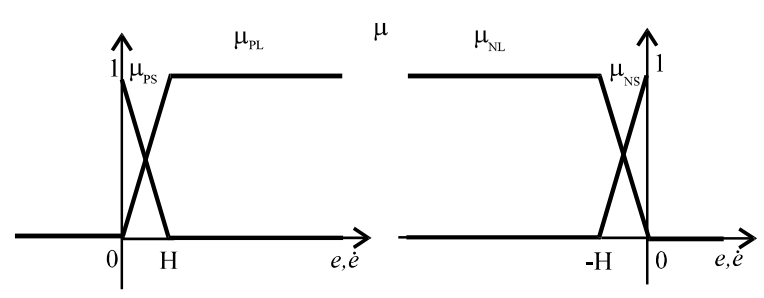

Fig.1: Four membership functions $e$ and $\dot{e}$

\section{B. Programmable Rule Base:}

$R 1$ : IF $e=$ PL AND $\dot{e}<0$ THEN $u(t+)=\mu \mathrm{PL}(e) . u(t)$ $R 2$ IF $e=$ PS AND $\dot{e}<0$ THEN $u(t+)=(1-\mu \mathrm{PS}(e)) \cdot u(t)$

$R 3:$ IF $e=$ NL AND $\dot{e}<0$ THEN $u\left(t^{+}\right)=-\mu \mathrm{NL}(e) \cdot u(t)$

$R 4$ : IF $e=$ NS AND $\dot{e}<0$ THEN $u(t+)=-(1-\mu \mathrm{NS}(e)) \cdot u(t)$

$R 5$ : IF $e=$ NL AND $\dot{e}>0$ THEN $u(t+)=\mu \mathrm{NL}(e) \cdot u(t)$

$R 6$ : IF $e=$ NS AND $\dot{e}>0$ THEN $u\left(t^{+}\right)=(1-\mu \mathrm{NS}(e)) \cdot u(t)$

$R 7$ : IF $e=$ PL AND $\dot{e}>0$ THEN $u(t+)=-\mu \mathrm{PL}(e) . u(t)$

$R 8$ : IF $e=$ PS AND $\dot{e}>0$ THEN $u(t+1)=-(1-\mu \mathrm{PS}(e)) \cdot u(t)$

To implement the FLC on a digital computer according to the expression:

$$
u(t)=u(k T) \text { and } u(t+)=\mathrm{u}((k+1) T)
$$

Where, $T$ is the sampling time. The following rule base is applied

$u(t)=u(k T)$ and $u(t+)=\mathrm{u}((k+1) T)$

Where, $T$ is the sampling time. The following rule base is applied $R 1: \operatorname{IF} e(k T)=\operatorname{PL}$ AND $\dot{e}(k T)<0$ THEN $\mathrm{u}((k+1) T)=\mu \operatorname{PL}(e(k T))$. $u(k T)$

$R 2$ : IF $e(k T)=\operatorname{PS}$ AND $\dot{e}(k T)<0 \operatorname{THEN~} \mathrm{u}((k+1) T)=$

$(1-\mu \mathrm{PS}(e(k T))) \cdot u(k T)$

$R 3$ : IF $e(k T)=\operatorname{NL}$ AND $\dot{e}(k T)<0$ THEN $\mathrm{u}((k+1) T)=$

$-\mu \mathrm{NL}(e(k T)) \cdot u(k T)$

R4: IF $e(k T)=\operatorname{NS}$ AND $\dot{e}(k T)<0$ THEN $\mathrm{u}((k+1) T)=$

$-(1-\mu \mathrm{NS}(e(k T))) \cdot u(k T)$

$R 5: \operatorname{IF} e(k T)=\mathrm{NL}$ AND $\dot{e}(k T)>0$ THEN u( $(k+1) T)=\mu \mathrm{NL}(e(k T))$ .$u(k T)$

$R 6: \operatorname{IF} e(k T)=\mathrm{NS}$ AND $\dot{e}(k T)>0$ THEN $\mathrm{u}((k+1) T)=$

$(1-\mu \mathrm{NS}(e(k T))) \cdot u(k T)$

$R 7: \operatorname{IF} e(k T)=\operatorname{PL}$ AND $\dot{e}(k T)>0$ THEN u $((k+1) T)=-\mu \operatorname{PL}(e(k T))$ .$u(k T)$

$R 8$ : IF $e(k T)=\operatorname{PS}$ AND $\dot{e}(k T)>0$ THEN $\mathrm{u}((k+1) T)=$

$-(1-\mu \mathrm{PS}(e(k T))) \cdot u(k T)$

Where, $\dot{e}(k T) \approx 1 / T[e(k T)-e((k-1) T)]$, with initial conditions

$y(0)=0, e(-T)=e(0)=r-y(0)$, $\dot{e}_{(0)=1 / T[e(0)-e(-T)]=0}$

C. Defuzzification: Select membership functions for the different control outputs from the rule base

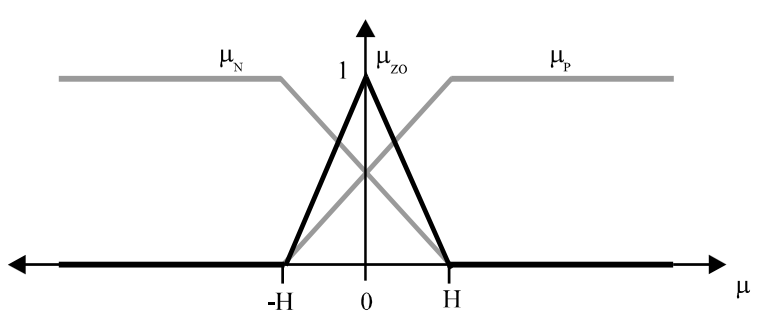

Fig. 2: Typical membership functions for $u$

In Figure 2 typical membership functions for $u$ is given. The overall control signal, $u$, is generated by a weighted average formula:

$$
u(k+1) T)=\frac{\sum_{i=1}^{N} \mu_{i} u_{i}(k T)}{\sum_{i=1}^{N} \mu_{i}} \cdot\left(\mu_{i} \geq 0, \sum \mu>0\right)
$$

Where control outputs $u_{i}(k T), i=1, \mathrm{~N}=8$ are from the rule base.

\section{Discretization of Conventional PID Controllers:} Digitization of the conventional analog PID controllers by:

$$
\mathrm{S}=\frac{2}{\mathrm{~T}} \frac{\mathrm{z}-1}{\mathrm{z}+1}
$$

Where, $\mathrm{T}>0$ is the sampling time for the PI controller, in Fig. 1 the block diagram for PI digital controller is given :

$$
\begin{aligned}
& \mathrm{u}(\mathrm{nT})=\mathrm{u}(\mathrm{nT}-\mathrm{T})+\mathrm{T} \Delta \mathrm{u}(\mathrm{nT}) \\
& \Delta \mathrm{u}(\mathrm{nT})=\tilde{\mathrm{K}}_{\mathrm{P}} \mathrm{v}(\mathrm{nT})+\frac{\tilde{\mathrm{K}}_{\mathrm{I}}}{\mathrm{T}} \mathrm{e}(\mathrm{nT})
\end{aligned}
$$

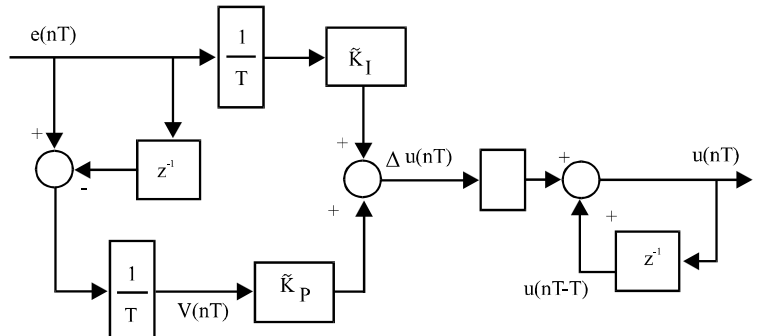

Fig. 3: The digital PI controller 
Modeling of the controlling unit: As an example, consider the voltage raising type-pulse controller. The detailed characteristics of which are given in ${ }^{[12]}$. The equivalent circuit in view of parasitic parameters of filtering elements is shown in Fig 4.

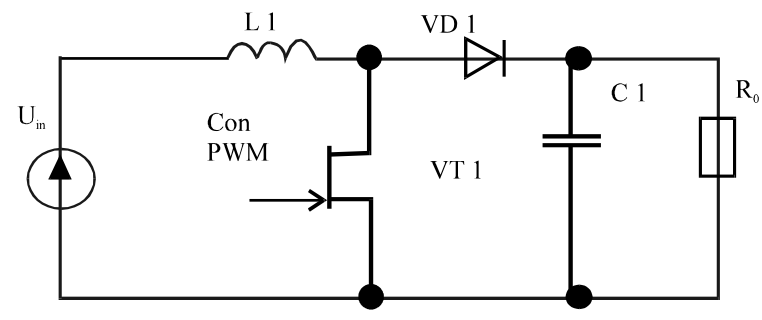

Fig.4: Equivalent scheme of boost-converter

Similar structure may be considered as a dynamic system with external disturbance, in particular, periodic. Using state variables, the system may be described as

$$
\frac{\mathrm{dY}}{\mathrm{dt}}=\mathrm{A}\left(\mathrm{S}_{\mathrm{f}}\right) \mathrm{Y}+\mathrm{b}
$$

Where,

$$
\begin{gathered}
A\left(S_{f}\right)=\left|\begin{array}{ll}
-\frac{R_{L}}{L}-\frac{R_{o} R_{c} S_{f}}{\left(R_{o}+R_{c}\right) L} & \frac{R_{o} S_{f}}{\left(R_{o}+R_{c}\right) L} \\
\frac{R_{o} S_{f}}{\left(R_{o}+R_{c}\right) C} & \frac{1}{\left(R_{o}+R_{c}\right) C}
\end{array}\right| \\
Y=\left|\frac{i_{L}}{u_{c}}\right|, \quad B=\left|\begin{array}{l}
\frac{U}{L} \\
O
\end{array}\right|
\end{gathered}
$$

$\mathrm{S}_{\mathrm{f}}$ is the pulse function which describes a state of the switch on the specified period of regulation. This function may be described as:

$$
\mathrm{S}_{\mathrm{f}}= \begin{cases}1, & (\mathrm{k}-1) \mathrm{T} \leq \mathrm{t}<\mathrm{t}_{\mathrm{k}} \\ 0, & \mathrm{t}_{\mathrm{k}}<\mathrm{t}<\mathrm{kt}\end{cases}
$$

Where, $\mathrm{T}$ is the period, $t_{k}$ - the moment of transition of the switch from one state to another on the specified period of regulation.

As an initial parameters of the model, the range of variation for the input voltage $U_{\text {in }}$ are set with triple overlapping from $20 \mathrm{~V}$ up to $60 \mathrm{~V}$, the range of variation of target resistance $\mathrm{R}_{0}$ with tenfold overlapping from $100 \mathrm{Ohm}$ up to $1000 \mathrm{Ohm}$ and the parasitic parameters of elements of the filter which define the losses and quality factor, accordingly, for inductance $\mathrm{L}=2 \mathrm{mH}$; capacitance $\mathrm{C}=100 \mu \mathrm{F} ; \mathrm{R}_{\mathrm{L}}=0,7$ $\mathrm{Ohm}$ and $\mathrm{R}_{\mathrm{C}}=0,2 \mathrm{Ohm}$.

The block diagram (see Fig.5) of the generalized indistinct controller consists of four elements ${ }^{[13]}$ :

1) 1 Fuzzification block, transforming input physical values $y_{i}$ into corresponding linguistic variables

$\mu\left(y_{i}\right)$;

2) Knowledge base, containing rules table for logic output block;

3) Logic output block, transforming input linguistic variables into output with some belonging functions Con;

4) Defuzzification block, transforming output linguistic variables into physical control influence.

Figure 6 shows the structure of P-type a fuzzy controller. In this case, the error of regulation $\varepsilon$ may be taken as the input information. The output information is the signal of the relative duration of conducting state of the switch Con $=t_{k} / T-(k-1)$. The structure of PI Fuzzy controller is shown in Fig. $7^{[13]}$. The input variables of this controller are, accordingly, the error of regulation $\varepsilon$ and its derivative ) $\varepsilon$. The output is the gain

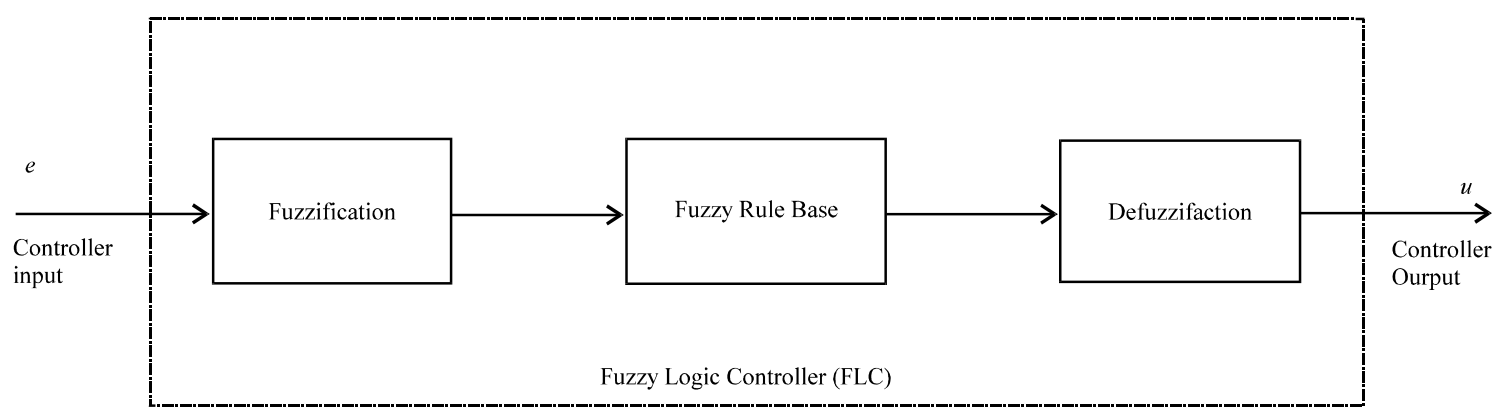

Fig. 5: General structure of a fuzzy logic controller 
Am. J. Applied Sci., 5 (6): 653-658, 2008

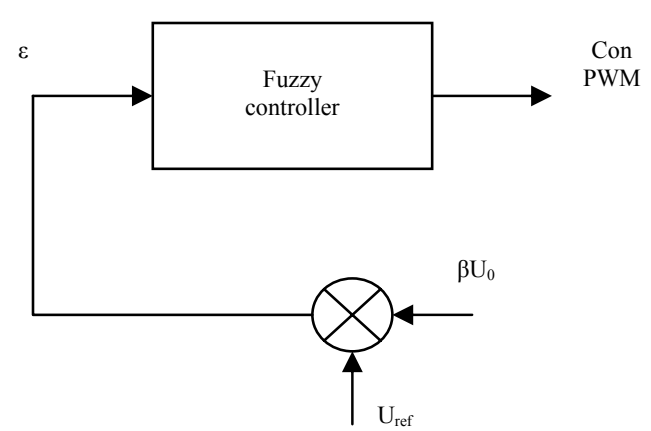

Fig. 6: Block diagram of P-type fuzzy controller

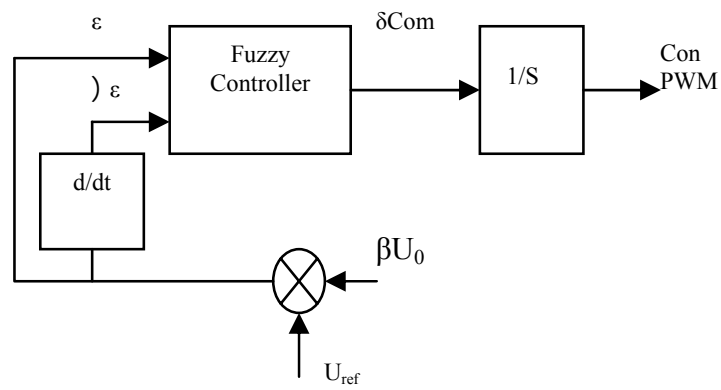

Fig. 7: Block diagram of PI-type fuzzy controller

of relative duration of the switch conducting state $\delta C o n$. The membership functions of the input linguistic variables are shown if Fig. 8.

It is expedient to divide a range of values of the normalized input variables ${ }^{[14]}$ into five linguistic terms: negative big (NB), negative small (NS), zero equal (ZE), positive small (PS) and positive big (PB).

With the application of indistinct logic, the logic choice for a P-type controller can be obtained on the basis of table -1 (the definition rules of the normalized error of regulation). The specified table is filled on the basis of the following logic expression:

If

$\varepsilon$ is $\mathrm{A}_{\mathrm{i}}$, then $\mathrm{Con}_{\mathrm{k}}$ is $\mathrm{C}_{\mathrm{j}}$,

Where, $A_{i}, B$ - terms of indistinct variables, $C_{j}$ - the centre of $\mathrm{j}$ - accessory function.

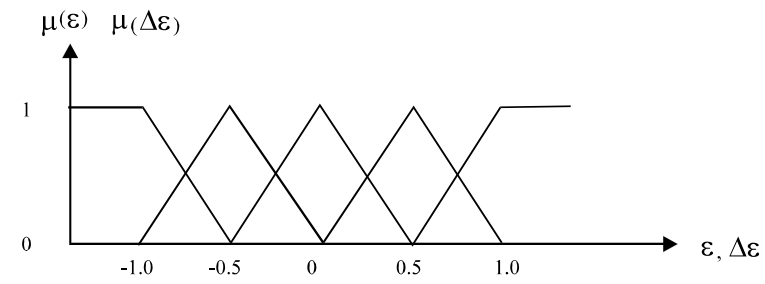

Fig. 8: Membership functions of the input linguistic variables.
Table 1: The definition rules of $\varepsilon$ for $\mathrm{P}$ controller

\begin{tabular}{llllll}
\hline & $\varepsilon$ & & & & \\
& NB & NS & ZE & PS & PB \\
\hline $\mathrm{C}_{\mathrm{j}}$ & 0 & 0.225 & 0.45 & 0.675 & 0.9 \\
\hline
\end{tabular}

Calculation of output signal Con of P-type controller is carried out according to the following equation:

$$
\mathrm{Con}_{\mathrm{k}}=\frac{\sum_{\mathrm{j}=1}^{\mathrm{n}} \mu_{\mathrm{j}}\left(\mathrm{kU}_{\mathrm{in}} \varepsilon\right) \mathrm{C}_{\mathrm{j}}}{\sum_{\mathrm{j}=1}^{\mathrm{n}} \mu_{\mathrm{j}}\left(\mathrm{kU}_{\mathrm{in}} \varepsilon\right)}
$$

Where, $k U_{i n}$ is the weighting factor which normalizes the input error $\varepsilon$ to the unit.

The logic choice for the PI controllers with the application of indistinct logic can be lead on the basis of table-2 (the definition rules for the normalized error of regulation). The specified table is filled on the basis of following logic expression:

If

$$
\varepsilon \text { is } A_{i} \text { and ) } \varepsilon \text { is } B_{i} \text {, then } \mathrm{Con}_{k} \text { is } C_{j} \text {. }
$$

\begin{tabular}{|c|c|c|c|c|c|c|}
\hline & & \multicolumn{5}{|l|}{$\varepsilon$} \\
\hline & & $\mathrm{NB}$ & NS & ZE & PS & PB \\
\hline \multirow{5}{*}{$\bar{\varepsilon}$} & PB & -0.3 & -0.35 & -0.45 & -0.65 & -1.0 \\
\hline & PS & 0.0 & -0.1 & -0.2 & -0.35 & -0.5 \\
\hline & $\mathrm{ZE}$ & 0.2 & 0.1 & 0.0 & -0.1 & -0.2 \\
\hline & NS & 0.5 & 0.35 & 0.2 & 0.1 & 0.0 \\
\hline & NB & 1.0 & 0.65 & 0.45 & 0.35 & 0.3 \\
\hline
\end{tabular}

Table 2: The definition rules of $\varepsilon$ for controller

Calculation for the target signal Con is carried out according to the following equation:

$$
\operatorname{Con}_{k}=\operatorname{Con}_{k-1}+0 \delta \operatorname{Con}_{k} \text {. }
$$

Where, 0 is a weighting factor which normalizes the target value Con to unity.

$$
\delta \operatorname{Con}_{k}=\frac{\sum_{j=1}^{n} \mu_{j}(y) C_{j}}{\sum_{j=1}^{n} \mu_{j}(y)}
$$

Where, $y$ - The input linguistic variable. The next values $(0.1,0.2,0.3)$ of 0 -coefficient were used when indistinct PI-regulator was simulated. 
Comparison for quality parameters of $\mathrm{P}$ and PI controllers: The following values were taken for comparison: $U_{\text {ref }}=3 ; \beta=0,04, k U_{i n}: 0,25 ; 0,5 ; 1,0 ; 2,0$; 4,$0 ; 0: 0,1 ; 0,2 ; 0,3$. The Simulation of the structure of fig. 4 allows defining the value of the static regulation error $>$ and the values of overcorrection 8 . For that, it was necessary to vary the parameters of an input voltage in the above-mentioned range and the factor of error scaling $k U_{i n}$. The results given in tables 3, 4 are obtained at a value of loading resistance $\mathrm{R}_{0}=300 \mathrm{Ohm}$. It is found that with the increasing of error scaling factor $k U_{i n}$, the static error is decreased and the overregulation is increased. The value of static error was defined for the input voltage $U_{i n}=60 \mathrm{~V}$ only, quasiperiodic oscillations were observed for other values of the input voltage. The estimation of the specified parameters of the controller structure of Fig. 7 isn't given, as it is practically static $(\approx 0,1 \%)$ with a periodic transient.

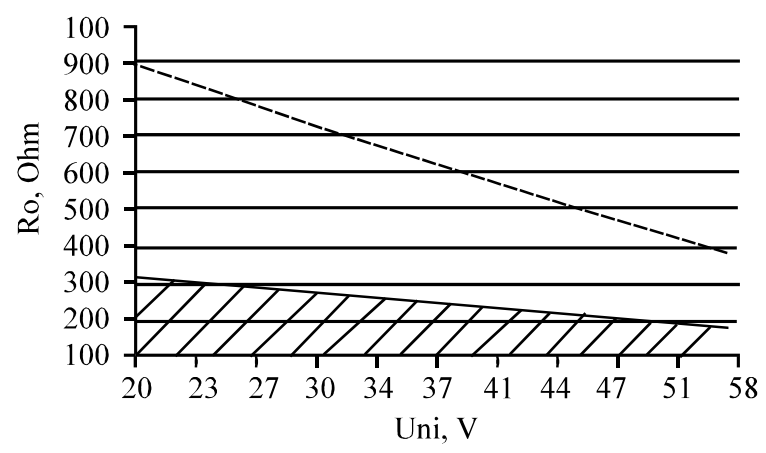

Fig. 9: Two parametrical diagram of synchronous mode zone of P-type fuzzy controller.

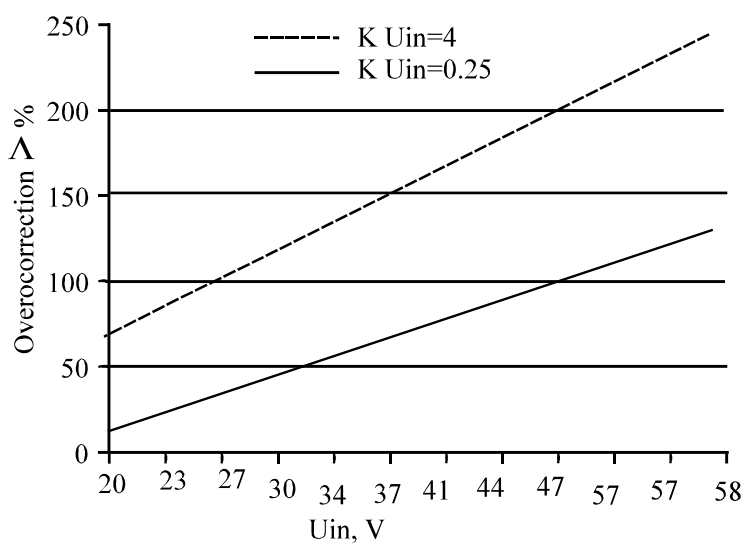

Fig. 10: Function of overregulation 8

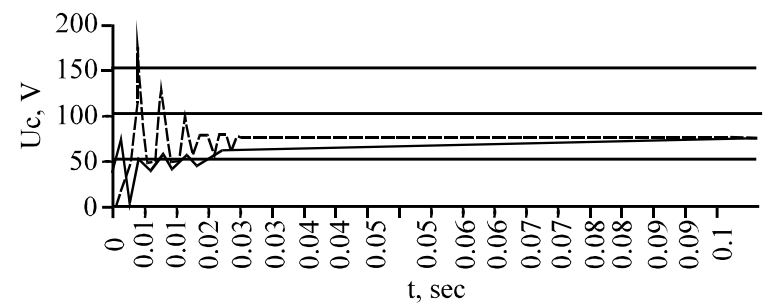

Fig. 11: Time-domain transient of the input current

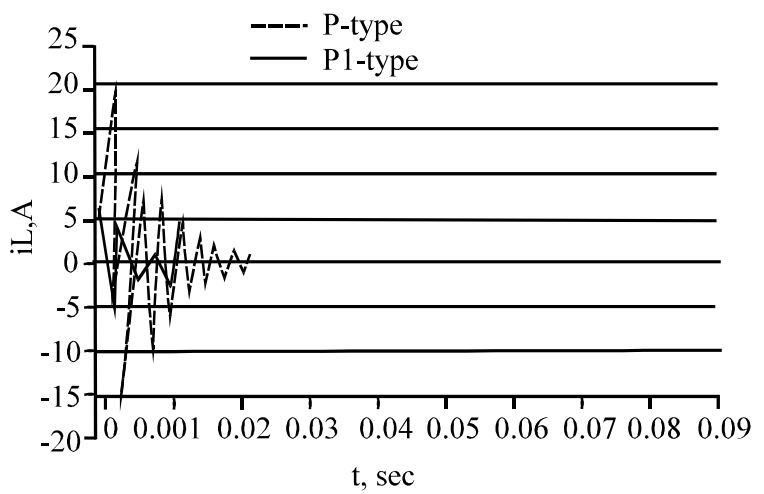

Fig. 12: The transient of the output voltage.

Table 3. The Static error of regulation $>\%$

\begin{tabular}{lrrrrl}
\hline \multicolumn{7}{c}{$\mathrm{kU}_{\text {in }}$} \\
\hline $\mathrm{U}_{\text {in },}$ \\
$\mathrm{V}$ & 0.25 & 0.5 & 1.0 & 2.0 & 4.0 \\
20 & 37.30 & 27.5 & 17.0 & 9.6 & $*$ \\
30 & 18.10 & 13.3 & 8.5 & 4.8 & $*$ \\
40 & 1.80 & 1.3 & 0.8 & 0.5 & $*$ \\
50 & -12.70 & -9.2 & -6.0 & -3.5 & $*$ \\
60 & -25.90 & -18.7 & $-12,3.0$ & -7.3 & -4.0 \\
\hline
\end{tabular}

Table 4. An overcorrection 8, \%

\begin{tabular}{lrrrrr}
\hline \multicolumn{7}{c}{$\mathrm{kU}_{\text {in }}$} & & & & \\
\hline $\mathrm{U}_{\text {in }}, \mathrm{V}$ & 0.25 & 0.5 & 1.0 & 2.0 & 4.0 \\
20 & 0.30 & 29.0 & 41.0 & 47.0 & 50.0 \\
30 & 38.00 & 73.0 & 88.0 & 95.0 & 98.0 \\
40 & 71.00 & 111.0 & 127.0 & 139.0 & 143.0 \\
50 & 102.00 & 148.0 & 171.0 & 180.0 & 185.0 \\
60 & 129.00 & 183.0 & 208.0 & 220.0 & 225.0 \\
\hline
\end{tabular}

Two-parametrical diagrams of synchronous mode existence areas are given for the structures of controllers on Fig. 6 and Fig. 7 accordingly in Fig. 9 and Fig. 10 for two values of $k U_{i n}$ and 0 . The area of existence of a synchronous mode is shaded. Timedomain diagrams of a current $i_{l}$ flowing in the coil and voltage across the capacitor $u_{c}$, are presented on Fig. 11 and Fig. 12, respectively. For a fuzzy P-type controller a value of $k U_{i n}=1$ is chosen, and for PI-type a value of $0=0.1$ is chosen. 


\section{CONCLUSIONS}

Fuzzy logic provides a certain level of artificial intelligence to the conventional controllers, leading to the effective fuzzy controllers. Process loops that can benefit from a non-linear control response are excellent candidates for fuzzy control. Since fuzzy logic provides fast response times with virtually no overshoot. Loops with noisy process signals have better stability and tighter control when fuzzy logic control is applied.

P Fuzzy controller has smaller sensitivity to the change in the input voltage, however, more sensitivity is observed to load changes. PI- Fuzzy controller has less sensitivity to load changes, where, higher sensitivity to the change of the input voltage is observed.

Analysis of transient and static error of regulation has shown advantage of an indistinct PI- controller for the output voltage over the P-type fuzzy controller.

P Fuzzy controller has faster transient as compared to PI controller, while, transient for PI Fuzzy controller is almost periodic.

\section{REFERENCES}

1. Verbruggen, H. B. and Bruijn, P. M., 1997. Fuzzy control and conventional control: What is (And Can Be) the Real Contribution of Fuzzy Systems Fuzzy Sets Systems, Vol. 90, 151-160.

2. Kowalska, T. O., Szabat, K. and Jaszczak, K., 2002. The Influence of Parameters and Structure of PI-Type Fuzzy-Logic Controller on DC Drive System Dynamics, Fuzzy Sets and Sysems, Vol. 131, 251-264.

3. Ahmed, M. S., Bhatti, U. L., Al-Sunni, F. M. and El-Shafei, M., 2001. Design of a Fuzzy Servo-Controller, Fuzzy Sets and Systems, vol. 124: 231-247.

4. Zilouchian, A., Juliano, M., Healy, T., 2000. Design of Fuzzy Logic Controller for a Jet Engine Fuel System, Control and Engineering Practices, Vol. 8: 873-883.
5. Zadeh, L. A., 1965. Fuzzy sets, Information Control, Vol. 8, pp: 339-353.

6. Liu, B. D., 1997. Design and Implementation of the Tree-Based Fuzzy Logic Controller, IEEE Transactions on Systems, Man, and Cybernetics, Part B: Cybernetics., Vol.27, No.3, 475-487.

7. Zhiqiang, G., 2002. A Stable Self-Tuning Fuzzy Logic Control System for Industrial Temperature Regulation, IEEE 1886 Transactions on Industry Applications.Vol.38, No.2: 414-424.

8. Shapiro, A. F., 2004. Fuzzy Logic in Insurance, Insurance: Mathematics and Economics, Vol.35, No.2 , 399-424.

9. Hayward, G. and Davidson, V., 2003. Fuzzy Logic Applications, Analyst, Vol.128, 1304-1306.

10. Peri, V. M. and Simon, D., 2005. Fuzzy Logic Control for an Autonomous Robot, North American Fuzzy Information Processing Society, NAFIPS 2005 Annual Meeting, 337- 342.

11. Sofiane Achiche, Wang Wei, Zhun Fan and others 2007: Genetically generated double-level fuzzy controller with a fuzzy adjustment strategy. GECCO'07, July 7-11.

12. Severns R., Bloom G., 1985. Modern DC toDC switchmode converter circuits. Van Nostrand Rainhold Co. NY.

13. So W. C., Tse C. K., 1996. Development of a Fuzzy Logic Controller for DC/DC Converters: Design, Computer Simulation and Experimental Evaluation. IEEE Trans. on Power Electronics, vol. PE11, January.

14. Parker D., 1987. Second order back propagation Implementation of an optimal 0(n) approximation, IEEE Trans. on PA \& MI. 